\title{
Asthma: A Risk Factor for Dental Caries?
}

This article has been reproduced with the permission of the Australian Dental Journal and at the request of the authors for the interest of practicing paediatricians.

\section{Thomas MS' ${ }^{1}$ Parolia A $^{2}$, Kundabala $\mathbf{M}^{3}$}

${ }^{1}$ Dr. Manuel S. Thomas, MDS Assistant Professor, Department of Conservative Dentistry and Endodontics, ${ }^{2} \mathrm{Dr}$. Abhishek Parolia, MDS, ${ }^{3} \mathrm{Dr}$. Kundabala M. MDS. All from the Department of Conservative Dentistry and Endodontics, Manipal College of Dental Sciences, Mangalore, Karnataka, India

Address for correspondence: Dr. Manuel S. Thomas, E-mail: manuel2dr@gmail.com

\author{
Abstract \\ This report points out a correlation between asthma and dental caries. It also gives certain guidelines on \\ the measures to be taken in an asthmatic to negate the risk of dental caries. \\ Key words: Asthma, Caries risk, Caries prevention, Dental caries
}

$A^{\text {nes }}$ ealthy set of teeth is important to smile confidently, chew the food properly and for proper phonetics. Most common dental ailment which can impair the aesthetics and function of the stomatognathic system is dental caries. It is a microbial disease of the calcified tissue of the teeth, characterized by demineralization of the inorganic portion and destruction of the organic substance. It is a disease with a multifactorial aetiology, as it is due to the interaction of four primary factors:
A. Host's susceptibility
B. Microorganism
C. Diet
D. Time

Factors which indirectly influence the primary causative factors are called risk factors ${ }^{1}$. A large number of studies have considered asthma as a risk factor in the occurrence of dental caries ${ }^{2-5}$. The possible way by which asthma affects the primary causative factors of dental caries is given in Figure 1.

Saliva is shown to play an important role in the maintenance of the oral health. Any factor which reduces the quality and quantity of saliva can increase the risk of dental caries ${ }^{1}$. Decrease in salivary flow rate can occur in asthmatics as a side effect of beta-2 agonist inhalers. Mouth breathing habit seen in asthmatics can also attribute to the dryness of mouth. This can jeopardize the protective ability of the saliva to clear the oral cavity of the fermentable substances and also decrease its buffering capacity. Asthmatic subjects have also shown a decrease in the output per minute of the total protein, amylase, hexosamine, salivary peroxidase, lysozyme and secretory $\lg \mathrm{A}$, in stimulated parotid saliva. This could affect the antimicrobial properties of saliva and thus can cause an increase in the Lactobacilli and Streptococcus mutans count ${ }^{6}$.

The reason for higher rate of caries which is observed in individuals with asthma can also be ascribed to the presence of fermentable carbohydrate in anti-asthma medications. Some dry powder inhalers contain sugar so that the patient can tolerate the taste of the drug when it is delivered. Frequent oral inhalation of these sugar containing drugs combined with the decrease in salivary flow rate may contribute to the increase in the risk of caries ${ }^{2}$. Frequent consumption of cariogenic drinks, in an attempt to wash away the taste of the inhaled medication and to counter the desiccating effect of mouth breathing and the reduction in the salivary flow caused by beta- 2 agonist, can also be a reason for the increase in the caries rate in asthmatics ${ }^{3}$. Additionally, asthmatic children have a restricted lifestyle where are not able to participate in other normal childhood activities. So their families may overindulge 
Possible reasons for higher prevalence of dental caries in asthmatics

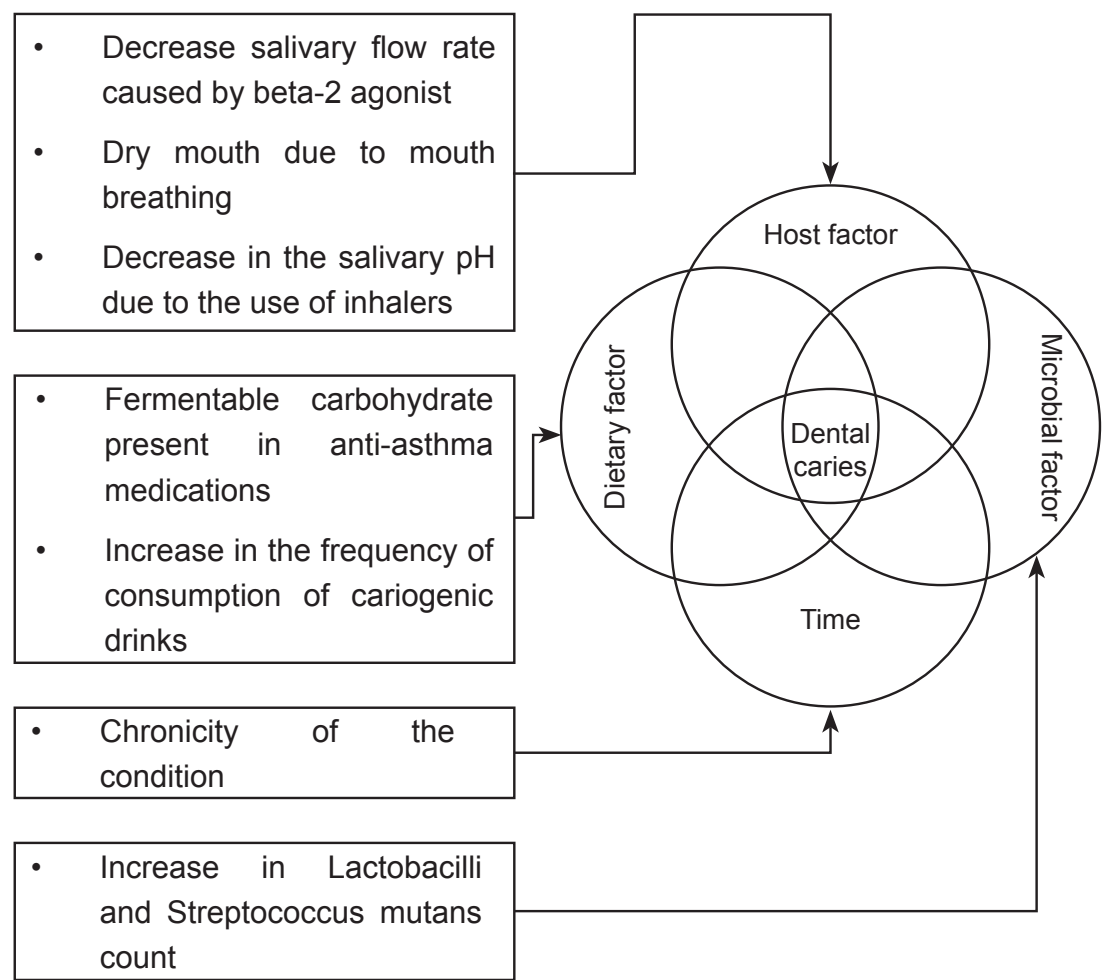

Protection measures to prevent the occurence of dental caries

- Educate asthmatic patients about their susceptibility to dental caries

- Encourage regular dental check -ups

- Advice patients to drink water more often to counteract dry mouth

- $\quad$ Advocate the use of fluoride mouth rinses daily

- $\quad$ Prescribe sugar free chewing gum to increase the salivary output

- Insist on thorough oral hygiene practices

- Advice the patients to rinse the mouth immediately after using inhaler

- Recommend the use of antimicrobial mouth washes

Fig 1: Showing possible reasons why asthma can be considered as a risk factor for dental caries and the measures to counter these problems.

them with frequent consumption of sweets leading to an increase in the caries levels ${ }^{4}$. Moreover, the oral hygiene procedures may be neglected due to the increase in the attention given to their general asthmatic condition ${ }^{5}$.

Asthmatics should be made conscious of the possible risk of dental caries and should be encouraged to have regular dental check-ups. Patients should be instructed to rinse their mouths after using an inhaler. They may be advised to use saliva substitutes, sip plain water and use fluoride mouth rinse daily to compensate for the xerostomia. The use of sugar-free chewing gum to stimulate salivary flow and buffer the oral acids should also be encouraged ${ }^{1}$.

Therefore, health care workers should be aware of the correlation between asthma and dental caries. They should educate asthmatic patients to follow precautionary measures to prevent the occurrence dental caries.

\section{References}

1. Axelsson P. Diagnosis and risk prediction of dental caries. 1st ed. Illinois: Quintessence Publishing Co, Inc; 2000.
2. Reddy DK, Hegde AM, Munshi AK. Dental caries status of children with bronchial asthma. J Clin Pediatr Dent 2003;27:293-295.

3. Stensson M, Wendt LK, Koch G, Oldaeus G, Birkhed D. Oral health in preschool children with asthma. Int J Paediatr Dent 2008;18:243-250.

4. McDerra EJ, Pollard MA, Curzon ME. The dental status of asthmatic British school children. Pediatr Dent 1998;20:281-287.

5. Shashikiran ND, Reddy VV, Raju PK. Effect of antiasthmatic medication on dental disease: dental caries and periodontal disease. J Indian Soc Pedod Prev Dent 2007;25:65-68.

6. Ryberg M, Moller C, Ericson T. Effect of beta 2adrenoceptor agonists on saliva proteins and dental caries in asthmatic children. J Dent Res 1987;66:1404-1406. 